\title{
Las transgresiones del tango electrónico: condiciones sociales contemporáneas y valoraciones estéticas en los bordes del tango
}

\author{
The Transgressions of the Electronic Tango: \\ Contemporary Social Conditions and Aesthetic Valuations \\ on the Fringe of the Tango
}

\author{
por \\ María Mercedes Liska \\ Facultad de Ciencias Sociales, Universidad de Buenos Aires, Argentina \\ mmmliska@gmail.com
}

\begin{abstract}
Este trabajo analiza la vinculación entre el tango electrónico y las corporalidades contemporáneas del tango en el proceso de legitimación de nuevas experiencias estético-musicales. Mediado por el cambio tecnológico y la difusión masiva, el tango electrónico ha suscitado un intenso debate acerca de su "autenticidad", su calidad artística y sus pretensiones ideológico-políticas, controversias que se agudizaron cuando inició su incorporación en algunos espacios de baile hasta que decayó su novedad en forma paulatina. En efecto, el tango electrónico encontró en los bailarines interesados en distanciarse del canon un público con el cual dialogar, al poner en escena las estrechas relaciones de sentido entre cuerpos y músicas. A partir del análisis de la producción musical y audiovisual y las descalificaciones de las que ha sido objeto, especialmente en el mundo del tango tradicional, este trabajo aborda cómo se encontró en el baile un ámbito de exploración estética, lo que reafirma a su vez las transgresiones corporales, el protagonismo femenino y las inflexiones en la norma heterosexual del tango histórico.

Palabras clave: Tango electrónico, corporalidades mediatizadas, música bailable, innovación estética, cambio tecnológico.
\end{abstract}

This article explores the relationships between the electronic tango and the contemporary corporeal features of the tango within the process of legitimizing new experiencies in the aesthetic and music fields. As a result of the technological changes and the diffusion of the electronic tango through society, an intense debate has set off about the "authenticity" of the electronic tango, its artistic value and its ideological and political connotations. The controversy deepened when some dance rooms incorporated electronic tango until it was no longer considered as something new. Dancers who wanted to keep the traditional canonic tango at a distance became the natural audience of electronic tango, as it sets forth the stronger relationships of meaning between bodies and music. On the basis of the analysis of the musical and audiovisual production and the objections coming specially from the traditional tango world, this paper intends to show how dancing became an environment for aesthetic exploration, while reaffirming bodily trangression, female protagonism and alterations of the heterosexual paradigm of the traditional tango.

Keywords: Electronic tango, mediated corporeality, dancing music, aesthetic innovation, technological change. 


\section{INTRODUCCIÓN ${ }^{1}$}

Luego de la paulatina recuperación del baile del tango en la ciudad de Buenos Aires durante la década del noventa, asentada sobre el retorno a la tradición², en el nuevo siglo XXI las prácticas matizaron la tendencia homogeneizadora de los movimientos en la instancia de baile. Durante la última década cobraron presencia aspectos como la exploración y la reflexividad (hasta incluso terapéutica) de la experiencia corporal y también cierta desnaturalización de la expectativa heterosexual, junto a la reconfiguración de las relaciones de género puestas en movimiento. En este proceso descentrado y ecléctico en el que se revalorizaron y resignificaron las actividades de baile, se pusieron en tensión los alcances y los límites de una concepción pluralista de la cultura. El tango electrónico emergió a la par de las nuevas prácticas de baile y desde entonces suscitó un intenso debate acerca de su "autenticidad" como producto cultural, su concepto estético-ideológico y su valor como objeto artístico. Con la etiqueta de ser un tango "para los que no les gusta el tango"3, las controversias se agudizaron cuando luego de su impacto mediático este comenzó a incorporarse en algunas clases de baile y milongas, hasta que su novedad decayó junto a su aparición en las pistas. Sin embargo, a pesar de lo efímero de los vínculos a lo largo del tiempo, esta relación permite visualizar las condiciones sociales de producción de la música.

Este trabajo analiza el diálogo entre música y baile y los alcances de esta vinculación en el proceso de legitimación de las nuevas propuestas estéticas del tango. Para ello se revisarán la polémica, los focos sobre los que recayeron las críticas y los modos en donde el tango electrónico encontró en las experiencias corporales un ámbito de exploración sonora. A la vez, veremos que su aparición reafirmó las transgresiones en las pistas de baile y ciertos desplazamientos respecto de las normativas de la práctica establecidas hasta el momento. Con este recorrido se reflexionará respecto de los procesos sociales y culturales contemporáneos y su relación con las transformaciones estéticas de la música popular.

\section{TRAYECTORIAS MUSICALES Y MEDIATIZACIÓN}

Para gran parte de los y las cultoras habituales del género, el tango electrónico surgió con un interés exclusivamente comercial que desmerecía, a priori, su calidad artística, y que obtuvo un éxito masivo debido a su replicación en los medios de

1 Este artículo aborda parte del análisis desplegado en la tesis de doctorado titulada Vanguardia "plebeya". El baile del tango en el paradigma transcultural (1990-2010) realizada en el marco del Doctorado en Ciencias Sociales de la Universidad de Buenos Aires, Argentina, la que fue defendida en marzo de 2013. La investigación fue financiada por becas doctorales del Consejo Nacional de Investigaciones Científicas y Técnicas de Argentina (CONICET) y por proyectos grupales dirigidos por Pablo Alabarces y financiados por los organismos, Subsidios de la Universidad de Buenos Aires para proyectos de investigación en Ciencia y Técnica (UBACYT) y el Fondo de Investigación Científica y Tecnológica (FONCYT), con sede en la Universidad de Buenos Aires (UBA).

2 Liska 2013.

3 Marchini 2007:80. 
comunicación. El malestar que provocó la irrupción de esta música actualizó una polémica sensiblemente conflictiva y recurrente en el tango, un género musical que a lo largo del siglo XX tuvo que adaptarse a las sucesivas fases tecnológicas de la industria cultural.

En Argentina el tango electrónico ocupó un lugar privilegiado en el debate acerca de las innovaciones estéticas contemporáneas por concentrar varios hitos clave en la problemática de lo cultural. Por un lado, la relación entre la cultura popular y la cultura masiva; por el otro, los avances tecnológicos, sus usos y los sentidos político-ideológicos que estos ofrecen o promueven y, finalmente, la condición de inferioridad frente a los juicios de valor de la música debido a su catalogación como género "bailable".

También conocido como electrotango o tecnotango, nació de la mezcla entre medios tradicionales de producción de sonido e instrumentos digitales (sonidos orgánicos y sintéticos, respectivamente), generando una combinación de texturas electrónicas con rasgos acústicos representativos del tango. A pesar de que los distintos conjuntos musicales que componen este segmento emplean procedimientos musicales bastante heterogéneos, el término fue utilizado en un sentido amplio. ${ }^{4}$ Asimismo, este segmento está emparentado con la denominada música dance, es decir, con la música electrónica bailable. A su vez, los subgéneros electrónicos que se asocian a este tango remiten a una particular porción conocida como música ambient, orientada a generar un clima específico en la fiesta electrónica dedicado a la distensión.

Para referir al tango, las propuestas aislaron, entre otros, rasgos como el timbre del bandoneón, una cadencia o un giro melódico, el marcato, el estilo vocal y la síncopa para las transiciones o puentes de enlace entre diferentes secciones musicales. En parte de su repertorio a veces resulta difícil identificar las marcas del tango salvo por algunas breves secciones que reafirman su adscripción. En este sentido, la cualidad tímbrica del bandoneón es un rasgo sólido que instituye la vinculación con el tango, aunque en varios casos el instrumento adquiere una función melódica más que armónica que da cuenta de cierta singularidad en su uso. Por tanto, el tango en la versión electrónica se sostiene estructuralmente desde sus rasgos melódicos (motivos). Entre sus características es importante destacar que el elemento vocal rompe con el aspecto narrativo de las letras, el que es suplantado por la reiteración de frases breves u onomatopeyas en alguna sección. Dentro de su repertorio también se realizan versiones (covers) de tangos históricos en cuyo caso se efectúa un "proceso de abstracción", que radica en atenuar las marcas genéricas convencionales. ${ }^{5}$

Otro recurso compositivo consiste en utilizar fragmentos de grabaciones para nuevas composiciones. Este procedimiento se realiza con el sampler, que es una tecnología digital de amplio uso desde la década del noventa, la que permite extraer

4 Los diferentes procedimientos se refieren a las prácticas de remix, mashup y sampleo. Para leer una descripción detallada de estos procedimientos musicales y su uso en el tango electrónico se puede consultar el trabajo de Greco y López Cano 2010.

5 Buch 2011:7. 
muestras de sonidos para ser usadas en nuevas creaciones. ${ }^{6}$ En el tango electrónico el sampler es utilizado para procesar grabaciones de tangos preexistentes, fragmentos de discursos políticos, paisajes sonoros o relatos de partidos de fútbol, entre otros. La técnica de sampleo es un rasgo distintivo del tango electrónico (si nos remitimos al tango histórico), así como su concepción musical basada en la cita y el reciclaje constante de diferentes sonidos que interpelan la memoria y la historia de la cultura ${ }^{7}$ en un contexto de innovación estética.

A su vez, también se vincula con otros géneros musicales contemporáneos como el rap y el hip hop, el jazz, el rock y el pop internacional, o con géneros rioplatenses como la murga o el candombe. De este modo, pueden identificarse canciones muy conocidas a modo de versiones "tecnotangueadas" de otros géneros musicales. Entonces, podemos decir que el tango electrónico se constituye como un hipertexto, un objeto transgenérico que engloba un género musical canónico mediante indicios textuales y paratextuales. Asimismo, su sonoridad se asienta en la yuxtaposición de elementos disímiles, es decir, no se trata de una fusión sino de una puesta intertextual.

Entre los principales referentes se encuentran los conjuntos Gotan Project, Bajofondo, Tanghetto, Narcotango, Ultratango, Tango Crash, Otros Aires, y San Telmo Lounge. ${ }^{8}$ Ellos están compuestos por músicos de variadas edades y experiencias musicales que en su mayoría son varones, aunque también participan algunas mujeres, que ocupan roles secundarios dentro de la formación, como es su modesta presencia en las interpretaciones vocales o en la ejecución de instrumentos convencionales. A su vez, sus integrantes, o al menos quienes crearon estas iniciativas musicales, no provienen del mundo del tango. Por otro lado, los conjuntos han surgido de argentinos residentes en el exterior o en asiduo contacto con las tendencias musicales de países como Inglaterra, Estados Unidos, Alemania o Francia. De esta manera, el tango electrónico es el resultado de las circulaciones y transacciones estéticas recientes entre diferentes territorios. Al respecto, Florencia Garramuño sostiene que el tipo de circulación contemporánea del tango describe flujos de intercambio y diálogo entre diferentes culturas con modos de fertilización cruzada que ya no parecen anclarse en la idea de "exportación" o "importación" de una cultura hacia otra (el tango que sale de Buenos Aires y es incorporado y "transculturalizado" en otro lugar), sino que en una suerte de creación de comunidades estéticas en las que interactúan lo local, lo nacional y lo transnacional de un modo semejante al que emerge en las nuevas nociones de ciudadanía, identidad y pertenencia en el mundo de las metrópolis actuales. ${ }^{9}$

El tango electrónico surgió a comienzos de la década 2000-2010 y ganó visibilidad rápidamente. Se pueden encontrar algunos antecedentes aislados en los

6 Ruesga Bono 2004.

7 Greco y López Cano 2010.

8 También se puede mencionar a otros grupos de tango electrónico como Tangodrims, Tango Fusion Club, Zona Tango y Malevo Sound Project.

9 Garramuño 2011. 
inicios de los noventa y escasamente en los ochenta. ${ }^{10}$ Más atrás, en la historia del tango encontramos a Eduardo Rovira y sus incursiones con música electroacústica, y a Astor Piazzolla, cuya producción musical es considerada por algunos músicos e investigadores como el antecedente directo del tango electrónico, aun cuando su música se aleja considerablemente de la música electrónica bailable. ${ }^{11}$ Pueden mencionarse también las búsquedas sonoras más recientes de Gustavo Beytelmann, un músico versátil que tuvo una incidencia destacada en el desarrollo musical del tango en Europa en las últimas décadas y que entre sus diversas actividades tuvo participaciones en el grupo Gotan Project. Sin embargo, es posible que la apreciación de Piazzolla como el padre "indirecto" de la criatura vaya más allá de los parentescos musicales, al ser el exponente histórico más visible en materia de irreverencia ante las convenciones estéticas del tango en otras épocas.

Los grupos Gotan Project y Bajofondo abrieron el surco en la batea de comercialización de la música que permitió el desarrollo de un campo de producción más amplio. El trío "transnacional" Gotan Project sintetiza gran parte de las características que se repitieron en el resto de los conjuntos y se convirtió en el mayor exponente de la versión electrónica del tango. ${ }^{12} \mathrm{Su}$ primer disco se editó en el 2001 luego de algunas iniciativas anteriores de uno de sus fundadores, el argentino Eduardo Makaroff, que no tuvieron trascendencia, ya que sus pares lo veían inviable en términos comerciales ${ }^{13}$ y en términos estéticos, sobre todo por considerar al tinte melancólico del tango como incompatible con el espíritu del dance. ${ }^{14}$

Sus integrantes reúnen variadas experiencias musicales y profesionales que se complementan, como la composición de bandas sonoras para películas y de avisos comerciales, así como el trabajo en producción y una vasta relación con el ámbito artístico-intelectual europeo. Asimismo, sus historias personales y familiares vinculadas al pensamiento y la militancia de izquierda tuvieron incidencia en las alusiones a la historia política de Argentina en las composiciones del conjunto. ${ }^{15}$

Es curiosa la similitud que tiene en esta breve sinopsis, el trasfondo subjetivo de Gotan Project con la historia y trayectoria profesional del multifacético músico y

10 Entre los antecedentes del tango electrónico en las décadas anteriores está el trabajo de 1992 de Sergio "Malevo" Bermejo (Malevo House Music. Malevo Records), las exploraciones sonoras del propio Eduardo Makaroff antes de conformar Gotan Proyect, y el tema Rosa porteña (1994) del grupo de Leo y Gastón Satragno. Anteriormente, Libertango de Astor Piazzolla en la versión de la jamaicana Grace Jones en 1981.

11 Para ver en detalle los rasgos musicales de la música de Piazzolla que pueden vincularse al tango electrónico, se pueden consultar los trabajos de Diego Fischerman y Abel Gilbert (2009) y el de Lautaro Díaz Geromet (2011).

12 Sus integrantes son el argentino Eduardo Makaroff, el francés Philippe Cohen-Solal y el suizoalemán Christoph Müller.

13 Buch 2011.

14 A causa de la dificultad que Makaroff encontró para llevar a cabo su propuesta con el tango estableció La revancha del tango como el título de la primera producción discográfica. Febrés 2008: 115.

15 La trayectoria personal y profesional de los músicos, así como la cronología del proyecto musical se puede consultar en Buch 2011. 
productor Gustavo Santaolalla, ideólogo del conjunto Bajofondo. ${ }^{16}$ Ambos proyectos artísticos combinan una sensibilidad artística e intelectual con un conocimiento acabado y un contacto estrecho con los dispositivos de producción y de circulación musical a escala masiva, que hacen del tango electrónico una música "incómoda".

Ciertamente se trata de objetos inscritos en una lógica masiva; tanto Gotan Project como Bajofondo editaron sus discos en sellos propios e independientes ${ }^{17}$ para luego asociarse a la compañía mayor Universal que se ocupó de la difusión y distribución de sus materiales fonográficos. ${ }^{18}$ Esta combinación está relacionada con las transformaciones establecidas por el capitalismo "informacional", a partir del cual la difusión asumió una problemática clave. Mientras que el volumen de música producida creció exponencialmente debido a los avances de la tecnología digital y la consecuente reducción de los costos de producción, las multinacionales destinan el grueso de su inversión en publicidad, marketing y espacios en los medios como la radio y la televisión a los que no acceden las discográficas independientes. ${ }^{19}$

Por otro lado, basta con mencionar la obtención de premios y su participación en los rankings de música internacionales, la cantidad de copias de discos vendidos, las visitas a sus canciones en sitios web o el intercambio de su música en Internet, las extensas giras por el mundo y los miles de concurrentes a sus recitales en vivo, además de la extendida difusión en medios de comunicación radiofónicos, programas televisivos y producciones cinematográficas en distintos países, para comprender que se trata de objetos masivos. ${ }^{20} \mathrm{~A}$ continuación veremos las repercusiones que tuvo en el contexto local.

16 La trayectoria musical de Gustavo Santaolalla comenzó a fines del sesenta en el rock. En los ochenta desarrolló su carrera como productor musical con proyectos osados como el mítico álbum $D e$ Usuahia a la Quiaca de León Gieco. En los noventa expandió este trabajo impulsando el llamado rock latino detrás de grupos como Café Tacuba, Divididos, Molotov, Bersuit Vergarabat, Juanes y Julieta Venegas, entre otros. Adquirió mayor visibilidad a fines de los noventa como productor de bandas sonoras de varias películas. Ganó consecutivamente dos premios Oscar, en 2006 por Brockeback Mountain (Secreto en la montaña) y en 2007 por Babel. También produjo el documental El café de los maestros en homenaje a artistas destacados del tango.

17 El sello Surco creado por Santaolalla y la discográfica Ya Basta! de Cohen Solal, integrante de Gotan Project.

18 Berenice Corti (2007) agrega que las ventajas de la producción musical independiente radican en el control total de la edición por parte del artista, mientras que las debilidades de este modelo giran en torno a la circulación del producto.

19 Negus 2005; Perrone y Zukerfeld 2007:88.

20 Algunos ejemplos concretos del impacto del tango electrónico a nivel internacional son los siguientes. Gotan Project vendió por la Revancha del tango más de un millón de discos (Febrés 2008). Bajofondo obtuvo un Grammy Latino como mejor álbum instrumental pop y Tanghetto fue nominado a ese premio en el 2004. Las visitas a temas de Gotan Project como Época, Diferenteo Confesión promediaban en el 2010 dos millones de personas (Buch 2011). Además, solo por mencionar algunas utilizaciones en medios masivos también en el exterior, figura la aparición de música de Gotan Project en una película protagonizada por Richard Gere y Jennifer López (Shall We Dance? 2004) y el uso frecuente de música del mismo grupo en la serie Nip/Tuck de la cadena Fox (Díaz Geromet 2011) o en la BBC (Buch 2011). También se usó música de Gotan Project en la sexta temporada de Sex and the City. En Brasil usaron música de Bajofondo en la telenovela La Favorita. Estos últimos datos fueron transmitidos en forma personal por Emilia Greco. 


\section{EL TANGO ELECTRÓNICO EN ARGENTINA}

En Argentina el tango electrónico se incorporó, con los medios de comunicación, en ciertos eventos destacados de la música electrónica como el Personal Fest o Creamfields y en algunos espacios de baile del tango: primero en las clases y después en las milongas ${ }^{21}$.

En el 2007 la Subsecretaría de Industrias Culturales de la Ciudad de Buenos Aires afirmaba que Gotan Project y Bajofondo (y los crossover en general) eran prácticamente el único segmento de venta formal de discos relacionados con el tango al público local. ${ }^{22}$ Por otra parte, si durante la década del noventa el tango histórico prácticamente desapareció de los medios masivos de comunicación, salvo los espacios temáticos en emisoras radiales como la radio pública del municipio de Buenos Aires, en la primera década de siglo XXI el tango electrónico fue rápidamente absorbido por estos medios.

Informativos de noticias y programas de actualidad política iniciaron el reemplazo de sus habituales sonoridades "de fondo" por estas tramas, sobre todo las más lineales, con predilección por las mixturas del sonido urbano y localista del bandoneón con el swing de las bases electrónicas, que permitían establecer una conexión de sentido muy concreta respecto del análisis sociopolítico de la Argentina contemporánea, ${ }^{23}$ un uso semejante al que tuvo la música de Piazzolla en los medios. ${ }^{24}$ Por último, también ha sido y es utilizado en series de ficción locales como en cortes originales. ${ }^{25}$ Estos espacios de repeticiones mediáticas han contribuido a la difusión del tango electrónico así como a enfatizar su ambigüedad retórico-enunciativa, mediante el modo en que se conjugó una apuesta creativa desafiante de la música "tradicional", que era ampliamente viable en términos

21 Nombre que reciben los lugares donde se baila el tango.

22 Marchini 2007: 80. Se debe tener en cuenta que la producción discográfica contemporánea de tango en Argentina es ampliamente independiente de las grandes empresas de comercialización y su venta se realiza de manera informal, fundamentalmente al momento del recital en vivo.

23 El monopolio multimedios denominado Clarín puede considerarse como el precursor en el uso del tango electrónico de programas radiales y televisivos de actualidad; en la televisión abierta por medio del noticiero Telenoche de Canal 13 y en el Canal de noticias $T N$ por cable, así como en su emisora radial A.M Radio Mitre, como es el caso del programa de Magdalena Ruiz Guiñazú que luego pasó a Radio Continental.

24 Un claro ejemplo ha sido el programa de Bernardo Neustadt (Díaz Geromet 2011:113). En relación con los usos mediáticos de la música de Piazzolla, Lautaro Díaz Geromet en este artículo hace referencia al trabajo de Omar Corrado titulado "Significar la ciudad: Astor Piazzolla y Buenos Aires”, Revista del Instituto Superior de Música, No 9 (2002). Buenos Aires: Universidad Nacional del Litoral, pp. 52-61.

25 La versión de Gotan Project del tango Cité tango de Piazzolla se hizo muy conocida por el éxito que tuvo la serie Los simuladores emitida por el canal Telefé en el 2002. Recientemente la serie $E l$ elegido, emitida por el mismo canal durante el 2011, tenía como corte musical central una canción de tango electrónico con una impronta rock-pop titulada Solo hay una ley. Esta fue creada por un grupo poco difundido hasta el momento llamado La fábrica de tangos, cuyos integrantes argentinos (Martín Murano y Pablo Mahmud Ahmad) residen en la actualidad en México. Por esta canción como cortina han sido nominados al premio Martín Fierro 2012. 
comerciales, junto con estar distante de la ausencia de ventas y difusión de otros tantos proyectos musicales vinculados al género.

Las críticas por parte del mundo del tango no tardaron en aparecer y se focalizaron en distintos aspectos. ${ }^{26}$ En principio, las controversias se refirieron a su legitimidad en tanto "tango". Se cuestionaba el uso del término para designar un repertorio "demasiado" alejado de las convenciones estéticas (canónicas) del género, como si con ello se tratara de legitimar la producción más que de marcar una pertenencia. En este sentido, algunas discusiones de corte académico intentaron evaluar qué pesaba más en términos de contenidos musicales: el tango o la música electrónica. ${ }^{27} \mathrm{Al}$ respecto, grupos como Bajofondo decidieron abandonar dicho rótulo para pasar a autodenominarse "música rioplatense contemporánea", 28 pero la etiqueta no tuvo prácticamente ningún efecto y sus discos siguieron abrevando a la batea comercial de "tango electrónico". Además, la apropiación de la modalidad electrónica por parte del baile del tango también lo acercó al género. En relación con esto es importante señalar que las investigaciones relativas a música popular han discutido y en parte consensuado que el concepto de género musical actualmente puede ser entendido más como una forma de reconocimiento de prácticas y no como una esencia. ${ }^{29}$

Otra de las críticas más enérgicas residió en la apropiación (y celebración) de la innovación tecnológico-musical. Decíamos que en la historia del tango (que abarca la historia de la industria cultural a lo largo del siglo XX), cada aparición de un nuevo soporte (el cine sonoro, la radio, la televisión) implicó el reajuste de la actividad musical. Joan E. Adell Pitarch señala que el desarrollo tecnológico pone en juego de manera constante el debate en torno a la "autenticidad" o verdad de la música, lo que implica en cierta medida que la tecnología termine siendo acusada de falsa, adulterante, contaminante y perturbadora ${ }^{30}$. La digitalización del sonido marcó un nuevo hito en estos cambios debido a su resuelta intervención en la producción además de la reproducción, con el consiguiente debate de plagio que trajo aparejado el sampleo y reutilización de los tangos históricos. ${ }^{31}$ En esta ofensiva respecto del uso de los nuevos recursos digitales en un género popular tradicional, la tecnología aparece vista como una supraentidad que se ubica por encima de las relaciones sociales. En efecto, dentro del sistema comunicacional las nuevas tecnologías imponen una lógica autónoma por encima del proceso de innovación vinculado a proyectos de organización social, ${ }^{32}$ obscureciendo el hecho de que

26 Estos testimonios fueron recogidos en la web y en entrevistas realizadas en forma personal a músicos, bailarines y personas del público, entre el 2007 y 2008.

27 Greco y López Cano 2010.

28 Esta autodefinición musical aparece en el cuadernillo que acompaña su cuarto disco, Mar dulce (2007).

29 Fabbri 2006.

30 Adell Pitarch 2004: 18. Para profundizar en la discusión acerca de "autenticidad" y tango electrónico ver también Liska (2008).

31 López Cano 2006.

32 Castells 1995. 
son el resultado de la acción humana. ${ }^{33}$ En definitiva, los instrumentos sintéticos aplicados al significante "tango" ejercen un aislamiento del sonido que habilita a pensar en un nuevo destierro de la noción de música como proceso social. Sin embargo, tampoco llegan a clausurar la posibilidad de tejer otros sentidos. Desde una apreciación benjaminiana, los dispositivos tecno-científicos pueden convertirse en herramientas para subvertir o atenuar el poder cultural del capital que las ha creado. ${ }^{34} \mathrm{El}$ tango electrónico da cuenta de que por lo menos existen fisuras, y que sus artefactos no están suturados. Más adelante retomaremos esta cuestión en el vínculo que el tango electrónico estableció con las prácticas de baile.

La oposición a esta propuesta musical refiere también a la ausencia del dramatismo canónico del tango interpretada como una reversión banal. En este punto sobresalieron las críticas por parte de músicos en la que se inscribe la repercutida declaración de Rodolfo Mederos, que habló del tango electrónico como expresión de la domesticación y unificación de las culturas: "la verdadera emoción la convoca lo que es genuino. Y hay que estar atento porque hay también emociones falsas". 35 En esta discusión se activa, en primera instancia, una concepción de lo dramático como sinónimo de "profundidad" y, en consecuencia, una crítica ideológica. Al respecto Esteban Buch recuerda la apuesta musical de Mederos de hace algunas décadas cuando fusionaba el tango con el rock, y señala la incapacidad actual del músico de reconocer en el tango electrónico la "energía de la juventud" de las nuevas generaciones. ${ }^{36}$ También, se puede pensar que, atenuando el dramatismo clásico, se repuso cierto carácter festivo del tango de los inicios vinculado estrechamente al baile, así como la ausencia de líricas narrativas alteró el sentido moralizador de larga tradición en su poética. ${ }^{37}$

Por otra parte, el grupo Tangocrash cuestionaba la utilización de sampleos de discursos de Evita o del Che Guevara en las composiciones de Gotan Project por estimarlo un recurso comercial, aun cuando ellos también realizan sampleos de discursos políticos pero orientados por un sentido irónico. ${ }^{38}$ Igualmente, resulta difícil imaginar que intervenir la música electrónica con reminiscencias tangueras y un discurso del Che haya constituido, a priori, una fórmula musical masivamente exitosa.

También se cuestionó su concepción "híbrida", es decir, la conformación de artefactos "bisagra" para su consumo en diferentes circuitos culturales: tanto en ámbitos destinados al tango como a la electrónica. Sin embargo, lo "híbrido" del tango electrónico puede entenderse como una intersección cultural que se aleja de la noción de identidades "puras". Según declara Julián Ruesga Bono: "Cuando se define la 'autenticidad' de tal o cual música, mediante un proceso de abstracción de rasgos, se tiende sospechosamente a olvidar las historias de mezclas en que se

33 Luhmann 2000.

34 Adell Pitarch 2004: 25.

35 Liska 2008: 238.

36 Buch 2011: 9.

37 Archetti 2003.

38 Greco y López Cano 2010. 
formaron. Se absolutiza un modo de entender la cultura, el arte y la música y se rechazan maneras heterodoxas de utilizar una lengua, entender y hacer arte o vivir las propias tradiciones". ${ }^{39}$

Hasta el momento, entre los músicos dedicados al empleo de instrumentos convencionales existe un rechazo bastante generalizado de las "facilidades" que brindan las nuevas tecnologías para hacer música, como si su uso no requiriera de competencias específicas. Es cierto que la tecnología digital alteró el sistema de signos que determinan el valor del músico y su producto, ${ }^{40}$ pero en el caso del tango electrónico esta consideración involucra el rechazo debido a una concepción estética diferente, que se distancia en forma considerable del paradigma virtuosístico, que se refiere a los juicios de valor en la música. ${ }^{41}$

En definitiva, el matrimonio del tango con la música electrónica bailable constituye un significante en tensión en una etapa de cambio tecnológico y estético. En todo caso, la distribución y difusión monopólica que se concentra en unos pocos objetos configura en gran medida la desigualdad actual que propicia la industria cultural. Al oscurecerse las operaciones de dominación propias de la lógica comunicacional, las discusiones circunscritas a cuestionar el valor artístico o el grado de "autenticidad" de una forma cultural nos dispersan de la comprensión de las asimetrías de poder y de reproducción de hegemonía respecto de la cultura.

La producción académica que existe actualmente atinente al tango electrónico es muy poca. No obstante, los trabajos a los que se ha hecho referencia con el uso del sampleo de María Emilia Greco y Rubén López Cano (2010), el de Esteban Buch acerca de la obra de Gotan Project (2011), además del artículo de Lautaro Díaz Geromet (2011) en relación con sus nexos con la obra de Piazzolla y más circunscrito al estudio de caso, conforman un material de gran densidad analítica. Justamente, me gustaría cerrar este apartado, dedicado a las expresiones críticas en contra de dichas apuestas musicales, con una de las discusiones abordadas en dos de estos trabajos.

Buch afirma que el tango electrónico reúne varias "polaridades ideológicas" 42 , hecho que nos remite a una discusión corriente en los estudios acerca de cultura popular y cultura masiva. En cuanto a su contenido político, tanto Buch como Greco y López $\mathrm{Cano}^{43}$ coinciden en señalar que lo que el tango electrónico reivindica no es un compromiso político sino que una percepción estética de la política. ${ }^{44}$ Respecto del sampleo de discursos políticos Greco y López Cano agregan: "Puede ser que la utilización de estos sampleos, más que una declaración de principios políticos de los músicos y su público, sea una apropiación, resignificación y reutilización de los íconos culturales sumamente flexibles que se adaptan a las

39 Ruesga Bono 2004: 23.

40 Adell Pitarch 2004.

41 Buch 2011.

42 Buch 2011: 2.

43 Buch 2011: 4.

44 Algunas de las composiciones con temáticas políticas son Época (2001), El capitalismo foráneo (2001) y Queremos paz (2001) de Gotan Project; DJ Perón (2003), Evitalos (2005) y Balbón (2005) de Tango Crash; Tangocrisis (2004) y Miedo a la libertad (2008) de Tanghetto. 
causas más variadas, vaciándose y llenándose continuamente de sentidos diversos como si se tratara de pancartas multiusos para las más heterogéneas afirmaciones políticas o culturales". ${ }^{45}$ Asimismo, sostienen que dicho sentido político está matizado por la levedad y atenuación característica de la música chill-out $^{46}$, junto con realizar una comparación con lo sucedido en los usos de la emblemática imagen del Che Guevara ${ }^{47}$ : "producto cultural entre la utopía moderna de un mundo que no pudo ser y la realidad posmoderna que, por imposible, no ha quedado más remedio que estetizarlo". 48

Es interesante ver qué ocurre con el sentido de ciertos objetos que el tango electrónico toma y hace circular por espacios en apariencia desprovistos de connotaciones políticas. No obstante, me inclino por problematizar estas consideraciones: ¿No se trata de un prejuicio basado en una concepción letrocéntrica de lo político en la música? ¿No reproduce el mismo discurso de que solo aquello densamente dramático puede ser considerado "profundo" y por lo tanto contestatario, reflexivo, irreverente?

De este modo se ha pasado revista por el surgimiento y desarrollo del tango electrónico en la primera década del siglo XXI y las principales discusiones y análisis que actualizó esta apuesta estética. Sin embargo, prácticamente no se ha hecho mención de la relación que este repertorio estableció con el baile, y particularmente, con el reposicionamiento de lo femenino en este universo. En el siguiente apartado nos dedicaremos a desentrañar estos vínculos recíprocos que habilitan otras comprensiones de la producción musical y su anclaje en las relaciones sociales.

\section{MÚSICA INSPIRADA EN LAS CORPORALIDADES CONTEMPORÁNEAS}

Es factible hacer notar el rol protagónico que asumieron las mujeres en el baile del tango durante la primera década del siglo XXI, aproximadamente. Pese al histórico dominio masculino establecido en el universo del tango aún en tensión, las prácticas han ido modificando los modos de relación entre los géneros. Ejemplos de ello son la autonomía que adquirieron las bailarinas en su carrera profesional o su lugar en la enseñanza, incluso, prescindiendo muchas veces del varón. De esta manera, las mujeres fueron creando propuestas de baile personales y espacios propios. De esta condición de posibilidad que se fue gestando gradualmente se creó, entre otros, el tango queer, una práctica asociada al lesbofeminismo intelectual y político, desde y para que las mujeres pudiesen bailar entre ellas. Pues bien, en la estética visual de la discografía de tango electrónico vemos una recurrente alusión, por un lado, al baile y, por el otro, al cuerpo femenino.

45 Greco y López Cano 2010.

46 Subgénero de la música electrónica de carácter distendido que sugiere, como lo indica el uso coloquial del término en el idioma inglés, "relajación".

47 Este análisis se basa en la circulación de la fotografía del Che Guevara tomada por Alberto Korda.

48 Greco y López Cano 2010. Aquí los autores hacen referencia a Iván de la Nuez, Fantasía roja. Los intelectuales de izquierda y la revolución cubana, 2006, p. 74. 
Uno de los trabajos de Gotan Project exhibe el torso de un cuerpo tatuado con el nombre del grupo (ver imagen 1), estética similar a una de las portadas de Bajofondo que muestra las piernas de una mujer recubiertas con medias de red (ver imagen 2).

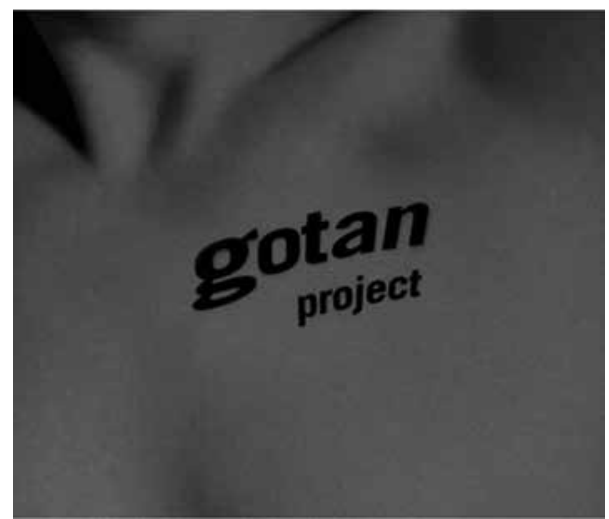

Imagen 1. Gotan Project.

La revancha del tango (2001).

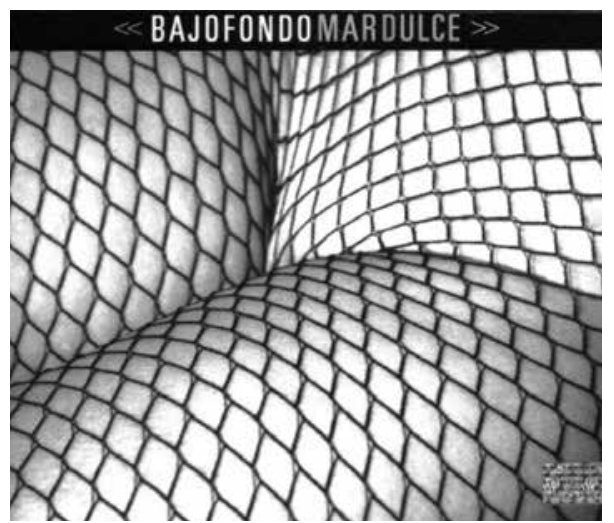

Imagen 2. Bajofondo. Mar dulce (2008).

Otra de las imágenes que presenta la discografía de Gotan Project contiene a tres mujeres con sus cuerpos completamente desnudos (ver imagen 3). El mismo conjunto establece su representación visual en otro trabajo mediante la puesta de las piernas de una mujer en situación de baile con una mancha de sangre en una de ellas; una lastimadura que puede connotar una performance intensa o desmesurada que remite también a un tipo de feminidad erótica (ver imagen 4).

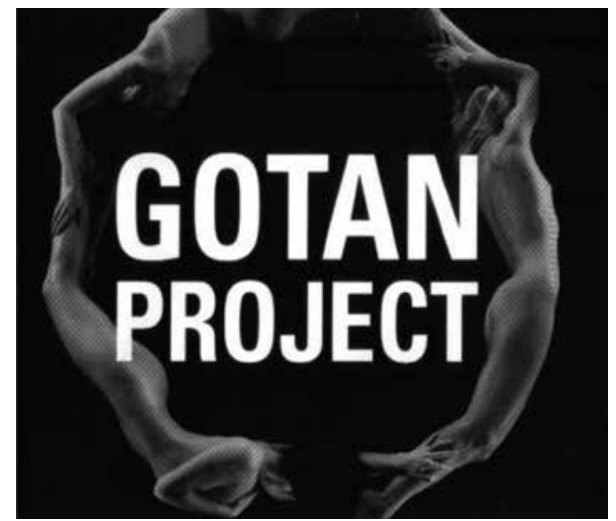

Imagen 3. Gotan Project. 3.0 (2010).

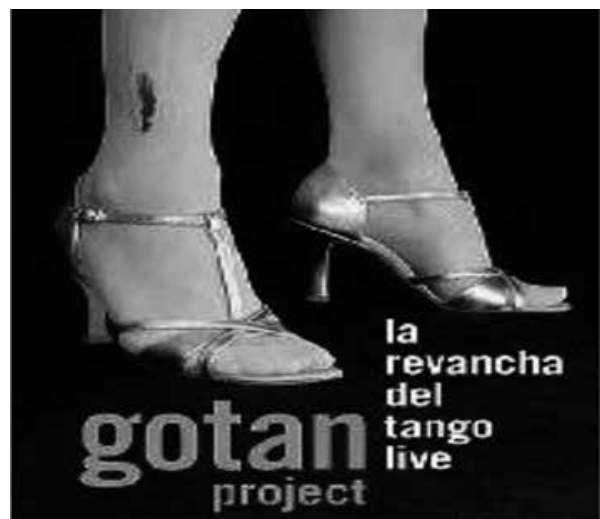

Imagen 4. Gotan Project. Portada del DVD sobre la gira "La revancha del tango" (2005).

Una de las portadas del grupo Narcotango presenta dos cuerpos abrazados en posición de baile que, como si no pudieran dejar de bailar, están contenidos por plásticos y un cinturón que los mantiene enlazados. Esta imagen también 
reproduce una carga erótica al colocar en segundo plano fotografías de la pareja besándose (ver imagen 5).

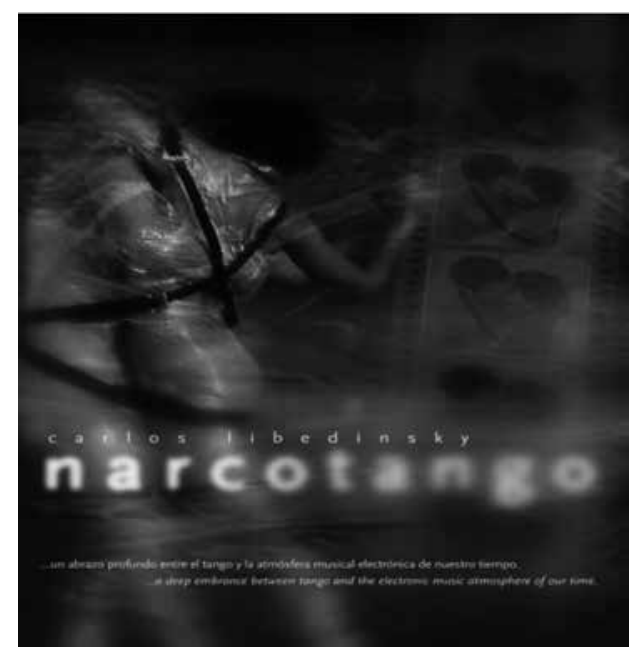

Imagen 5. Narcotango. Narcotango (2003).

Una portada de Tanghetto muestra a una pareja en posición de baile pero en este caso destaca el cuerpo de un varón, desplazando la lectura erótica y sensual de lo femenino (ver imagen 6). Por otra parte, una de las tapas de disco de Otros Aires declara su anclaje en el baile desde una retórica tradicional (ver imagen 7).

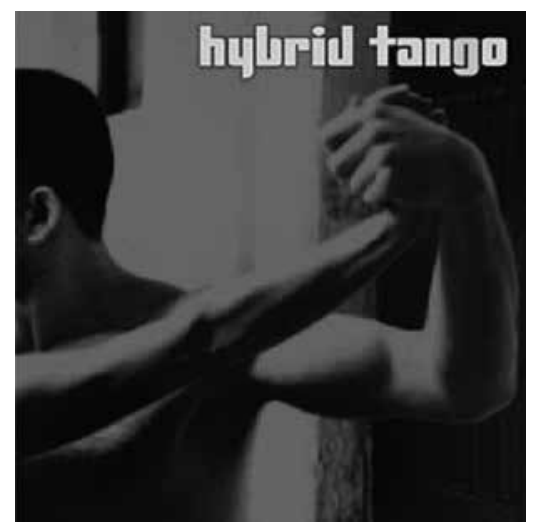

Imagen 6. Tanghetto. Hybrid tango (2004).

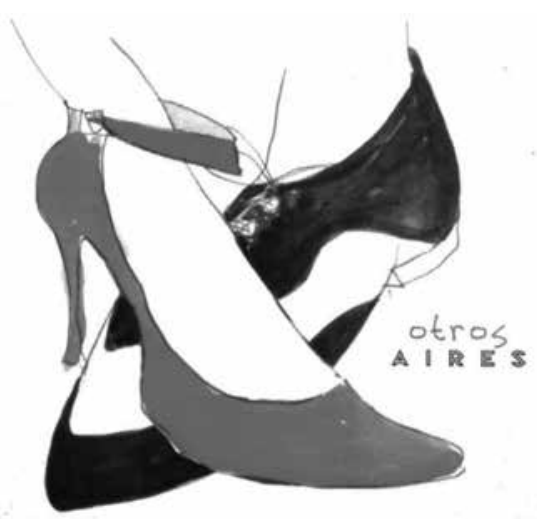

Imagen 7. Otros Aires. Otros Aires (2004).

Finalmente, la portada de Tango Crash refiere explícitamente al baile pero en este caso por oposición a este, o al menos al estilo canónico, representado con una figura for export tachada con el símbolo de "prohibido" y parodiada por la intervención de un cerdo que los está observando. Asimismo, el nombre del disco (Bailá querida) interpela lo femenino (ver imagen 8). 


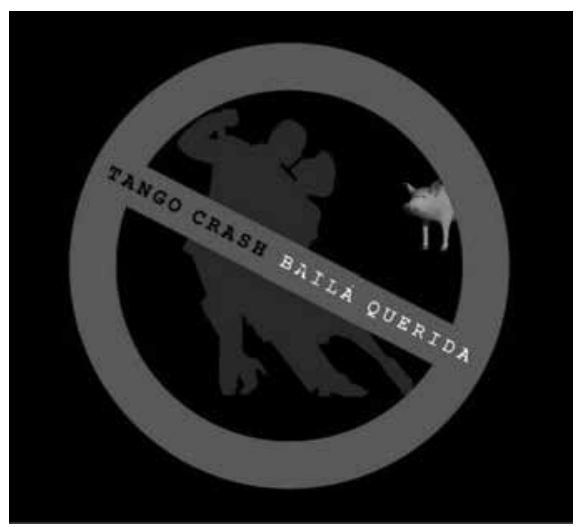

Imagen 8. Tango Crash. Bailá Querida (2008).

Es posible pensar que en su mayoría la estética visual del tango electrónico remite a una corporalidad que intenta despegarse del cliché del tango pero no de su representación erótica (salvo Tanghetto), ya que se focaliza en la experiencia corporal como un atributo casi exclusivamente femenino, con guiños a la sensualidad heteronormativa. Acerca de Gotan Project, Buch considera que una de las aristas que el grupo actualiza de la histórica dinámica geopolítica del tango (Europa-Argentina) se dirige en este sentido: "De los fundadores de Gotan Proyect, fue Eduardo Makaroff quien tuvo primero la intuición que en aquel momento histórico de fines de siglo la imagen exótica/erótica del tango convergía con la evolución de la tecnología y la nueva legitimidad de las 'músicas híbridas' para hacer viable el proyecto de un tecnotango". ${ }^{49}$

A su vez, estos referentes visuales aparecen en los recitales. Las actuaciones en vivo de los conjuntos mencionados cuentan con un marcado trabajo de la imagen mediante recursos de iluminación, proyecciones de videos y performances de baile. Los videos exhiben una variedad de evocaciones de la ciudad de Buenos Aires en distintas épocas y paisajes urbanos en general, o fragmentos de películas preferentemente antiguas, entre otros. Entre algunas de las variadas referencias a lo femenino y al baile, en la presentación en Buenos Aires del disco 3.0 de Gotan Project, ${ }^{50}$ cada tema fue acompañado de la proyección de un video que reiteraba escenas de baile entre mujeres mediante un efecto visual muy recurrente en el conjunto. Este consiste en una figura en espejo, mientras que los movimientos median entre una estilística del tango y una gestualidad propia de la danza académica contemporánea distante de la sensualidad clásica, con vestimentas que a menudo difieren de la estética convencional. ${ }^{51}$

49 Buch 2011: 10.

50 Teatro Gran Rex, 15 de septiembre de 2011.

51 Según Buch, todos los videos de Gotan Project pertenecen a Prisca Lobjoy, y sostiene que en ellos converge una estética posmoderna del patriotismo y el estilo glamour de la publicidad de lujo (2011: 8). 
Por su parte, el grupo Narcotango suele incorporar en sus recitales a bailarines de la escena de tango nuevo, uno de los estilos de baile alternativos desarrollado en los últimos años. Entre ellos, uno de los predilectos es el bailarín Mario Rizzo y sus exhibiciones unipersonales de "break-tango" (imbricación de un estilo gestual "hip-hop" junto con la gestualidad del tango tradicional). El mismo bailarín también participó en el videoclip de Bajofondo del tema Pa'bailar (2007) en una situación de baile social donde intercala imágenes de baile suelto al estilo dance con momentos de baile de pareja enlazada. ${ }^{52}$ Allí, dentro de una tumultuosa pista de baile se destacan los cuerpos femeninos que, distantes de la sensualidad clásica del tango, enfatizan un discurso de seducción conjugando parejas de baile homo y hétero de ambos sexos. En el mismo año, el grupo Tanghetto realizó un llamativo video de su tema Mente frágil que elude nuevamente el cliché erótico heterosexual y que narra, sin declives sexistas, el encuentro erótico-afectivo de dos mujeres a partir del tango. ${ }^{53}$ La sinopsis narrada se basa en una mujer que muestra insatisfacción en su vida cotidiana y conflictos en su relación de pareja (hétero). Sorpresivamente encuentra a un bandoneonista tocando en la calle y a otra mujer que también se detiene a escucharlo. Sus miradas se encuentran y terminan bailando juntas. Luego, en otra escena se las puede ver muy alegres compartiendo un encuentro sexual. ${ }^{54}$ Aquí puede observarse claramente la apoyatura de ambas expresiones, musical y corporal, y algunas de las experiencias sociales que irrumpieron en el tango a cargo de las mujeres.

Finalmente, el video de Gotan Project del tema Diferente (Lunático, 2006), constituye una reflexión acerca de las distintas posibilidades del amor por medio del tango. El corto describe una noche de milonga en un sitio tradicional en la que se desarrolla una exhibición de baile donde, por el mismo efecto de duplicación señalado antes, se juega con una pareja heterosexual, la que por momentos se torna en una pareja de mujeres y por momentos de varones. Paralelamente, una mujer y un varón que individualmente se dirigen a la milonga invitan a pensar que esperan encontrarse allí, hasta que al final se muestra (en un tono sugerido, no explícito) que cada uno buscaba encontrarse con una compañía del mismo sexo. La letra de la canción dice lo siguiente: "En el mundo habrá un lugar/para cada despertar/ un jardín de pan y de poesía/ Porque puestos a soñar/fácil es imaginar/ esta humanidad en armonía/Vibra mi mente al pensar/ en la posibilidad/de encontrar un rumbo diferente/Para abrir de par en par/ Los cuadernos del amor/del gauchaje y de toda la gente/Qué bueno che, qué lindo es/ reírnos como hermanos/por qué esperar/ para cambiar/ de murga y de compás".

Es importante señalar que además del tango queer existen otros espacios pensados para posibilitar el baile del tango entre parejas gays, como la milonga La Marshall que funciona desde el 2003. Igualmente, el baile entre parejas del

52 El video se puede ver en: http://www.youtube.com/watch?v=yuuxfmzddbs\&feature=related [Fecha de consulta: 4 de junio de 2012].

53 El tema Mente frágil pertenece al disco Emigrante (2004).

54 El video está disponible online en: http://www.youtube.com/watch?v=NTxVXcdgncg [Fecha de consulta: 4 de junio de 2012]. 
mismo sexo, sobre todo de mujeres, es una práctica que se ha asimilado bastante y puede verse en diferentes milongas sin estar relacionada necesariamente con las elecciones erótico-afectivas de las practicantes.

Particularmente Tanghetto y Narcotango son los conjuntos que, con residencia en Buenos Aires, conocen y han tenido una relación efectiva con las prácticas de baile en la ciudad. Esta experiencia se vislumbra claramente en sus abordajes musicales concernientes a la temática y en sus diferencias respecto de ciertos rasgos exóticos que aparecen en los otros conjuntos. Carlos Libedinsky, integrante e impulsor de Narcotango, dice lo siguiente: "El baile ya venía renovándose en los últimos diez, quince años, los bailarines ya empezaban a bailar distinto, aun con los tangos tradicionales. Yo sentía una especie de transculturación. El baile estaba siendo desarrollado por gente contemporánea pero la música no. El electrotango ayudó a completar ese proceso". 55; "Y a mí, como bailarín, me encantaba bailar Di Sarli o Pugliese, pero llegado un momento de la noche notaba una necesidad corporal de algo distinto, en mí y en los otros". ${ }^{6}$

Una de las dos mujeres que actúan en el video de Tanghetto es Roxana Gargano, quien por varios años organizó La Marshall junto con Augusto Balizano. De hecho, media una relación personal que hizo que este conjunto se presente en vivo en el I Festival Internacional de Tango Queer en Buenos Aires (2007).

Mediante estas descripciones hemos visto que el tango electrónico se identificó con corporalidades, formas de erotismo y relaciones de género nutridas de situaciones reales en las prácticas de baile actuales. Es posible preguntarse en qué medida dicha producción reforzó su gesto irreverente a partir de estos referentes periféricos para el mundo del tango. Lo que puede afirmarse es que su vínculo con relaciones sociales concretas facilitó la apropiación por los bailarines de esta música, generando un guion para que estas relaciones actúen y se vuelvan inteligibles, legitimando así su existencia en un contexto de críticas y rechazo.

También pueden pensarse cuáles son los efectos de sentido que produce la referencia a lo femenino en un contexto marcadamente masculino. En este punto se genera una cierta distancia del agenciamiento de género en las prácticas de baile, con algunas similitudes respecto de la poética del tango de 1920, en la que se expresaba una ansiedad masculina referida al ingreso de las mujeres en la vida pública y los consiguientes procesos de autonomía relativa en algunos órdenes. ${ }^{57}$ Así, se reitera una misma dinámica de atracción y de ansiedad que generan las formas de poder y legitimidad que asumen las mujeres, al tiempo que producen cosificación y control sobre ellas limitándolas a ser representadas y no como actores de su propia representación.

Además, Susan McClary, en lo que ha sido uno de los trabajos seminales de la musicología feminista norteamericana, Feminine Endings, señala que en la música aparece una tensa relación entre las mujeres y las nuevas tecnologías, debido a

\footnotetext{
55 Nota periodística: "Un sampler y una quebrada”, 2006, s/a: http://www.tangodata.com.ar/ homenotasyentrevistas.php [Fecha de consulta 20 de diciembre de 2006].

56 http://weblogs.clarin.com/cronicas/archives/2006/08/8_gotan_electronico.html

57 Savigliano 1995; Archetti 2003; Saikin 2004; Gil Lozano 2008.
} 
que dicha relación atenta con el imaginario de lo femenino con lo natural, lo irracional y lo emocional. ${ }^{58}$ En este sentido, el tango electrónico realiza dos operaciones simultáneas: da cuenta de las transformaciones sociales contemporáneas en virtud de las relaciones de género, mientras que establece los límites, es decir, señala el dominio masculino de esa representación, ya que las mujeres pasan de ser hacedoras a ser protagonistas de la representación masculina. No obstante, a continuación se verá desde qué lugares las mujeres que bailan se apropiaron de la música.

\section{EL USO DE LA MÚSICA PARA LA CONFIGURACIÓN DE CORPORALIDADES EMERGENTES}

Entre las repercusiones que estas versiones del tango suscitaron en el mundo del baile, Buch señala que desde un comienzo Gotan Project concibió sus trabajos para ser insertados en dichos espacios: primero en los ámbitos de música electrónica (dance) y luego en lugares de tango. ${ }^{59}$ De modo casi simultáneo a la generación de los primeros proyectos musicales, en los primeros años del siglo XXI el tango electrónico se difunde en las milongas de París y al poco tiempo se convierte en un repertorio infaltable en las pistas de esa ciudad. ${ }^{60}$ Asimismo, Buch sostiene que, de manera "independiente" a la producción musical, el "tango nuevo" había iniciado una búsqueda y cuestionamiento, sobre todo de las interacciones de género en el baile mientras que el tango electrónico contribuyó "a una dinámica de cambios en torno a cuestiones generacionales, estilísticas e ideológicas". ${ }^{61}$ En efecto, esta relación fue recíproca, porque Buch también señala que la estética del grupo musical ha ido ajustándose a esta práctica. Si en el primer disco los temas duraban más de 6 minutos, luego se adoptaron al formato estándar de canción (de 3 a 4 minutos), el que es más aplicable a la pista del baile. ${ }^{62}$

Por su parte, en Buenos Aires en el 2007 una profesora de tango nuevo comentaba que para ella en un determinado momento empezó a ocurrir que las grabaciones de las orquestas típicas de la década del cuarenta colisionaban con lo que se estaba gestando en los cuerpos e incluso que en las clases, a sus alumnos (mayormente gente joven), les resultaba mucho más fácil articular los movimientos con el tango electrónico. ${ }^{63}$ Por esos años otros profesores coincidían en decir que algunos temas de tango electrónico eran útiles en las clases para realizar determinados ejercicios, como por ejemplo la práctica de giros, y también se lo relacionaba con ciertos contenidos técnicos innovadores, como el cambio de roles

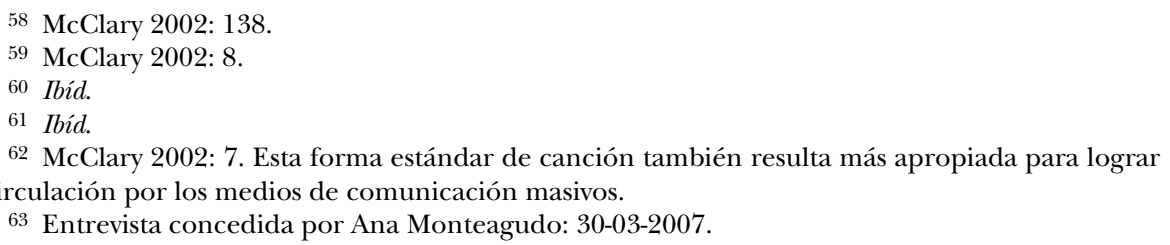


en el movimiento. ${ }^{64}$ Asimismo, los bailarines profesionales de tango nuevo, a la hora de realizar exhibiciones de danza, comenzaron a privilegiar el uso del tango electrónico. ${ }^{65}$ Por su parte, la organizadora de una milonga que se denominó "La antimilonga" sostiene que en su espacio se consagraron conjuntos como Otros Aires y San Telmo Lounge. ${ }^{66}$ Mientras tanto, los organizadores de la milonga gay La Marshall se jactan de ser los primeros en poner en funciones a la versión electrónica en la pista de baile. ${ }^{67} \mathrm{En}$ una entrevista, Balizano relata una conversación con el musicalizador (Mario Orlando) de su milonga en los comienzos, en la que este le decía: "Hay que lograr un estilo de música que sea particular de La Marshall. Y que las personas que quieran bailar esa forma, ese estilo, o esa calidad de música, tengan que venir exclusivamente a La Marshall". ${ }^{68}$ Finalmente, Roxana Gargano, quien protagonizó el video Mente frágil de Tanghetto, describe lo siguiente: "Lo que hacen los chicos [Tanghetto] y nosotros va en un paralelo, cubriendo otros espacios que quizás la propuesta tradicional no le da. Es como que estamos trabajando en paralelo con estas propuestas alternativas. Para mí hay como una red que se crea sola, como que es necesario vincularse, más que nada por una contención. Fue de casualidad poder conectarme con ellos y después sí continuamos trabajando juntos. Ahora ya estamos proyectando hacer una película, un corto, unas ideas que tienen que ver con el tango, pero con transmitir cosas que están pasando ahora". ${ }^{69}$ De esta manera el tango queer y el tango electrónico alimentaban una relación de reciprocidad al encuentro de sus alteridades, siendo que además estas apuestas conformaban un núcleo minoritario dentro del circuito tanguero convencional.

De este modo se puede afirmar que las nuevas propuestas de baile establecieron una relación de carácter contractual con el tango electrónico. La idea de contrato social $^{70}$ resulta útil para explicar la interrelación entre la producción musical y las nuevas propuestas de baile del tango en la construcción de sentido, además de la manera en que se vincularon desde un mismo horizonte de expectativas. En definitiva, las transformaciones estético-musicales terminaron de comprenderse por medio de las performances. ${ }^{71}$

Finalmente, los vínculos entre el tango crossovery las corporalidades emergentes se estrecharon en un determinado momento y en los últimos años se disiparon. En los ámbitos de baile, el tango electrónico fue desplazado por la incorporación de

64 Liska 2009. La relación entre tango electrónico y dinámica corporal innovadora pude observarla claramente en la clase realizada por Lucas de Buenos Aires en el marco de la II Maratón de Tango Queer en Buenos Aires (2011).

65 Por ejemplo los renombrados Dana Frígoli y Pablo Villarraza, pareja de bailarines que crearon el Estudio DNI. Luego, Villarraza se desvinculó de este espacio.

66 http://www.lavikinga.eu/ [Fecha de consulta: 27-11-2011].

67 En Buenos Aires Gay Friendly, 2006. Entrevista a Roxana Gargano, Mariana Docampo Falcón, Andrea Merellano y Carlos Meliá <http://www.bue.gov.ar/especiales/?id=12 > [Fecha de consulta: 8-11-2007].

68 En Gasió 2011: 4124.

69 Entrevista concedida por Roxana Gargano: 26-08-2008.

70 Lejeune 1991.

71 Cook 2007:12. 
otros tipos de músicas. Este segmento de producción abrió camino a la posibilidad de bailar, respetando ciertas pautas básicas del tango, con cualquier tipo de música en varios de los espacios de un público más joven. El éxito mediático y comercial del tango electrónico también hizo que estos espacios dejaran de tener un contacto directo con el baile. Por ejemplo, una de las organizadoras del festival de tango queer cuenta que en el 2011 quiso programar a Otros Aires pero la invitación se vio frustrada por los elevados costos que el grupo demandaba.

El apoyo mancomunado fue dejado atrás en la medida en que tanto las nuevas expresiones corporales como la nueva música fueron adquiriendo un estatus y legitimación social. El tango electrónico en los últimos años pasó de ser marginal a incorporarse al mundo del tango, hecho del que da cuenta el megaevento anual de tango organizado todos los años por el gobierno de la Ciudad de Buenos Aires. Dicho evento se distribuye en torno a un lugar principal donde se realizan las actividades centrales y en subsedes donde se programan actividades "secundarias". En el 2008, la única mención al tango electrónico en el cronograma de recitales fue la "milonga electrónica", que se realizó en uno de los espacios periféricos: el boliche Niceto Club, un lugar absolutamente desplazado del circuito del tango. ${ }^{72}$ En el festival del 2009 se produjo un cambio considerable respecto del anterior. Los grupos Tanghetto, Narcotango y Otros Aires fueron programados para el lugar epicentro del evento ${ }^{73}$, en un recital que acompañaron una cantidad considerable de bailarines jóvenes, pero también de edades más avanzadas. En este sentido, en la "vidriera" del tango en la ciudad, reiteradamente canónica hasta el momento, el tango electrónico logró su instalación entre el 2008 y 2009. Esta incorporación tuvo continuidad en el festival 2010, con presentaciones de Luciano Superville y Ultratango. En el 2011 fue programada una "fiesta electrónica" en el espacio central, aunque en este último tuvo una importante repercusión la incorporación de la escena under del tango dentro de las actividades centrales, acompañada de un discurso donde los organizadores políticos asumían por primera vez la existencia de un tango "legítimo" abierto a la pluralidad de estéticas musicales. ${ }^{74}$

En el caso del baile, se incorporó en el 2008 en la grilla de clases que ofrecen estos mismos festivales: una de Augusto Balizano de La Marshall y en el 2011 circularon folletos del gobierno de la ciudad que, bajo el nombre "Ciudad diversa", difundían el festival de tango queer como parte de la oferta cultural gay-friendly porteña.

72 Niceto Club es un lugar ubicado en la zona de Palermo Soho vinculado a la música popular experimental, al pop, al rock y a la electrónica.

73 El lugar ese año fue Harrods, conocido otrora como la Tienda Harrods, antiguo espacio comercial de la clase alta que se encontraba cerrado y abandonado. Fue reciclado y actualmente se utiliza para fines culturales.

74 El viraje estético del evento anual aparece descrito en los párrafos de presentación de la programación impresa del Festival-Mundial 2011, firmados por el propio Mauricio Macri, entonces alcalde de la Ciudad de Buenos Aires: "Hoy, el tango encuentra nuevos horizontes creativos acordes con la época y se ha transformado en un punto de encuentro para jóvenes y adultos orgullosos de su tradición y dispuestos a ampliar sus fronteras". 


\section{ÚLTIMAS CONSIDERACIONES}

Este trabajo analizó la relación entre música y baile y los alcances de esa vinculación en un contexto específico: el proceso de legitimación de las nuevas propuestas estéticas del tango en una etapa de cambio tecnológico.

Señalamos que a comienzos del siglo XXI las prácticas de baile del tango en la ciudad de Buenos Aires asumieron nuevos registros corporales basados en la exploración, la reflexividad y la inflexión en las normas de género. El tango electrónico emergió a la par de esas experiencias y suscitó un acalorado debate estético y político que se agudizó cuando comenzó a utilizarse en las situaciones de baile, hasta que su novedad decayó.

Se pasó revista por los focos principales sobre los que recayeron las críticas y los modos en donde el tango electrónico encontró en las experiencias corporales un ámbito de exploración sonora, con la reafirmación de las transgresiones en las pistas de baile y en los desplazamientos respecto de las normativas de la práctica establecidas hasta ese momento.

Se consideró que el tango electrónico se identificó con corporalidades, formas de erotismo y relaciones de género nutridas de situaciones reales en las prácticas de baile recientes. En particular, que construyó parte de su estética visual sobre las experiencias femeninas, filtrando las aún poco visibles relaciones erótico-afectivas entre mujeres; desde la fantasía al orden de lo cotidiano, de la inscripción masculina y heterosexual en esa mirada al terreno de lo que está por fuera de ella. No obstante, todas compartieron el hecho de considerar cierta ruptura del tango respecto de la expectativa heterosexual obligatoria.

De esta manera, analizar el tango electrónico en relación con el baile permitió observar algunos de los usos que tuvieron las nuevas producciones musicales mediadas por la tecnología y su intervención en los procesos de construcción de significados sociales..$^{75}$ También se podría invertir la frase y decir que las tecnologías socialmente disponibles que intervienen en la música produjeron un cierre de sentido de la práctica corporal. Más allá de establecer un antes y un después, el dominio discursivo y control operacional de las tecnologías no escapan a las condiciones sociales de su emergencia y apertura en la dimensión de la agencia ${ }^{76}$. En este sentido, Héctor Schmucler sostiene que las tecnologías existen porque han sido percibidas como útiles según una concepción del mundo. ${ }^{77}$ Por su parte, Ramón Pelinski señala que si se asume que la música es una experiencia del cuerpo, en cuyo proceso reside la significación, la dicotomía música-ser humano se diluye..$^{78}$ La noción de la música como la extensión del cuerpo repone la relación social

75 Es necesario aclarar que las tecnologías digitales disponibles no son en sí la novedad, ya que existen hace tiempo. Lo nuevo se manifiesta en su modo de aplicación en la música popular y en la gestación más reciente de un paradigma estético.

76 De acuerdo con Giddens 1995.

77 Schmucler 2007: 234.

78 Pelinski 2000: 138. 
como su rasgo intrínseco, así como recupera el valor analítico de las sonoridades empleadas para la acción del cuerpo.

Para finalizar, resulta interesante señalar que en el recital que Gotan Project realizó en Buenos Aires en el 2011, en dos o tres oportunidades los músicos invitaron a bailar al público. En el sector pullman del recinto, varias de las personas que estaban sentadas atrás de todo se levantaron y fueron hacia delante, pero varios de los que estaban sentados allí se quejaron porque no veían y los entusiastas se tuvieron que volver a sentar. Solo al final del recital, durante los bises, todos se levantaron. En general hubo poca participación del público aunque los asistentes querían hacerlo pero no sabían cómo. No podían cantar porque el formato de la voz no es narrativo; tampoco podían bailar porque el ámbito era un teatro. En la nueva música (¿bailable?) aparece una notoria evocación al cuerpo al tiempo que paradójicamente se establece una pasividad de los mismos. De modo que puede pensarse que el tango electrónico apela a un cuerpo imaginario (el sensorium posmoderno) y prescinde materialmente de él. Sin embargo, más allá de que la versión electrónica constituye un fenómeno acotado dentro de los nuevos procesos de producción y consumo musical, ha catalizado las demandas de las nuevas corporalidades del tango y ha contribuido a completar socialmente a esos cuerpos.

\section{BIBLIOGRAFÍA}

Adell Pitarch, Joan-Elies

2004 "Entre la autenticidad y la impostura: música y nuevas tecnologías", en Julián Ruesga Bono (editor). Intersecciones. La música en la cultura electro-digital. Sevilla: Arte/facto, Colectivo Cultura Contemporánea, pp. 17-30.

Archetti, Eduardo

2003 Masculinidades. Fútbol, tango y polo en la Argentina. Buenos Aires: Antropofagia.

Buch, Esteban

2011 "El proyecto tango de Gotan Proyect", Revista Afuera, VI/10 (mayo), pp. 1-11. Disponible en: www.revistaafuera.com [Fecha de consulta: 5-03-2012].

Castells, Manuel

1995 La ciudad informacional: tecnologías de la información, reestructuración económica y el proceso urbano-regional. Madrid: Alianza.

CoOK, Nicholas

2007 "Mudando o objeto musical: abordagens para a análise da performance", Música em contexto. Revista do programa de Pós-Graduaçao em Música, I/1. Brasilia: Universidad de Brasilia, pp. 7-32.

Corti, Berenice

2007 "Las redes del disco independiente: apuntes sobre la producción, circulación y consumo", en Las industrias culturales en la Ciudad de Buenos Aires [AAVV, concurso de ensayos 2007, trabajos premiados]. Buenos Aires: Observatorio de Industrias Culturales, pp. 55-79.

De LA Nuez, Iván

2006 Fantasía roja. Los intelectuales de izquierdas y la revolución cubana. Barcelona: Debate. $143 \mathrm{pp}$. 


\section{Díaz Geromet, LaUtaro}

2011 "Buenos Aires Hola Cero Electrónico: un acercamiento a la relación entre la música de Astor Piazzolla y el tango electrónico”, Revista del Instituto Superior de Música, No 13. Santa Fe: Universidad Nacional del Litoral, pp. 111-123.

FABBRI, FRANCO

2006 “Tipos, categorías, géneros musicales. ¿Hace falta una teoría?”, Música popular: cuerpo y escena en la América Latina. VII Congreso IASPM-AL [Rama Latinoamericana de la Asociación Internacional para el Estudio de la Música Popular], 19-24 de junio de 2006. La Habana: en prensa.

Febrés, Xavier

2008 De Carlos Gardel al tango electrónico. Barcelona: RBA libros.

Fischerman, Diego y Abel Gilbert

2009 Piazzolla: el mal entendido. Un estudio cultural. Buenos Aires: Edhasa.

Garramuño, Florencia

2011 "Comunidades estéticas: nuevos diálogos musicales", Revista Afuera, VI/10, pp. 1-10. Disponible en: http:/ /www.revistaafuera.com/articulo.php?id=168\&nro $=10$ [Fecha de consulta: 5-03-2012].

Gasió, Guillermo

2011 La historia del tango 21. Siglo XXI, década I, 2 da parte. Buenos Aires: Corregidor.

Giddens, ANTHony

1995 La construcción de la sociedad. Bases para la teoría de la estructuración. Buenos Aires: Amorrortu.

Gil Lozano, Fernanda

2008 "Género y representaciones femeninas en el cine sonoro argentino", en María Celia Bravo, Fernanda Gil Lozano y Valeria Pita (editoras). Historias de luchas, resistencias y representaciones. Mujeres en la Argentina, siglos XIX y XX. San Miguel de Tucumán: Edunt, pp. 391-406.

Greco, María Emilia y Rubén López Cano

2010 "Evita, el Che, Gardel y el gol de Victorino: funciones y significados del sampleo del tango electrónico", ¿्Popular, pop, populachera? El dilema de las músicas populares en América Latina.

IX Congreso de la Rama Latinoamericana de la Asociación Internacional para el Estudio de la Música Popular en América Latina (IASPM-AL), 1-5 de junio de 2010. Caracas: en prensa.

Lejeune, Philippe

1991 "El pacto autobiográfico", Suplemento Anthropos, No 29. Madrid: Endimión, pp. 47-62.

Liska, María Mercedes

2008 "La renovación de los valores de autenticidad o el tango electrónico como producto del mercado", Actas del VIII Congreso de la Asociación Internacional para el Estudio de la Música Popular (IASPM-AL). Lima, 18-22 de junio de 2008. Disponible en: http:/ /es.scribd.com/doc/74186914/Autenticidad-TangoElectronico [Fecha de consulta: 30-07-2013]. 
2009 "El tango que regula cuerpos ilegítimos-legitimados", Trans, Revista Transcultural de Música, $\mathrm{N}^{\circ}$ 13, s/p. Disponible en: http://www.sibetrans.com/trans/trans13/ art04.htm [Fecha de consulta: 30-07-2013].

2013 "La revitalización del baile social en Buenos Aires. Neoliberalismo y cultura popular durante la década de 1990”, Ethnomusicology Review , № 18, pp. 1-21. Los Ángeles: University of California (UCLA): Disponible en http:/ / ethnomusicologyreview.ucla.edu/journal/volume/18/piece/702

López Cano, Rubén

2006 "La música ya no es lo que era: una aproximación a las posmodernidades de la música", Revista Boletín Música, $\mathrm{N}^{\circ}$ 17, pp. 42-63. Versión online disponible en: www. lopezcano.net [Fecha de consulta: 20-10-2012].

LUHMANN, NikLAS

2000 La realidad de los medios de masas. México: Anthropos.

Marchini, Jorge

2007 El tango en la economía de la Ciudad de Buenos Aires. Buenos Aires: Subsecretaría de Industrias Culturales.

McClary, Susan

2002 [1991] Feminine Endings. Music, Gender, E् Sexuality. Londres: University of Minnesota Press.

\section{Negus, Keith}

(2005) [1999] Los géneros musicales y la cultura de las multinacionales. Barcelona: Paidós.

\section{Pelinski, Ramón}

2000 "La corporalidad del tango: breve guía de accesos", en Invitación a la etnomusicología. Quince fragmentos y un tango. Madrid: Akal, pp 252-281.

Perrone, Ignacio y Mariano Zukerfeld

2007 Disonancias del capital. Música, tecnologías digitales y capitalismo. Buenos Aires: Ediciones Cooperativas.

Ruesga Bono, Julián

2004 Intersecciones. La música en la cultura electro-digital. Sevilla: Arte/facto, Colectivo Cultura Contemporánea.

Saikin, Magali

2004 Tango y género. Identidades y roles sexuales en el tango argentino. Stuttgart: Abrazos.

Savigliano, Marta E.

1995 Tango and the Political Economy of Passion. San Francisco, California: Oxford Westview Press.

\section{SCHMUCler, Héctor}

2007 "La sociedad de la información: una construcción del capitalismo tardío", en Damián Loreti, Guillermo Mastrini y Mariana Baranchuk (editores). Participación y democracia en la sociedad de la información. Buenos Aires: Prometeo, pp. 235-248. 